\title{
Cyclosporine-induced Synthesis of Endothelin by Cultured Human Endothelial Cells
}

\author{
Timothy E. Bunchman and Craig A. Brookshire \\ Department of Pediatric Nephrology, St. Louis University, St. Louis, Missouri 63104
}

\begin{abstract}
Endothelin (ET), a peptide synthesized by endothelial cells (EC), causes a decreased renal blood flow and glomerular filtration rate and an increased mean arterial pressure when infused in animals. In tissue culture, ET causes smooth muscle cell (SMC) proliferation and contraction by influx of extracellular calcium, which is inhibited by calcium channel antagonists. Infusion of cyclosporine (CSA) hemodynamically parallels ET action, and knowing that CSA effects EC, we hypothesize that the vasoconstrictive effects of CSA are a result of ET synthesis by EC.

Varying concentrations of CSA were incubated with EC resulting in ET present in the supernatants in a dose-dependent manner peaking at $75 \%$ above basal activity. Coincubation of either cremophor alone or cycloheximide with CSA resulted in minimal ET present in the EC supernatants $(P<0.01$ each).

Incubation of conditioned media from CSA-treated EC with SMC caused proliferation at $114 \%$ above basal activity, which did not occur in the presence of CSA alone $(P<0.01)$. This activity is specifically inhibited in the presence of an anti-ET antibody or nonspecifically in the presence of calcium channel antagonists $(P<0.01$ each $)$.

Therefore, CSA stimulates EC synthesis of ET which in turn causes SMC proliferation. This action is inhibited by the coincubation of a specific antibody to ET or a calcium channel antagonist. These findings may help in the understanding of CSA-induced hypertension and vasculopathy. (J. Clin. Invest. 1991. 88:310-314.) Key words: transplantation - calcium antagonists • smooth muscle cell
\end{abstract}

\section{Introduction}

Endothelin (ET), ${ }^{1}$ a 21 amino acid peptide, is known to be synthesized by endothelial cells in animals and man (1-3). Endothelin acts upon smooth muscle cells (SMC) as well as glo-

This project was presented in part at the 1989 American Society of Nephrology meetings, Washington, DC.

Address correspondence and reprint requests to Dr. Timothy E. Bunchman, Assistant Professor of Pediatric Nephrology, University of Michigan Medical Center, Taubman HCC, Box 0318, Room 1924, 1500 East Medical Center Drive, Ann Arbor, MI 48109-0318.

Received for publication 4 April 1990 and in revised form 14 March 1991.

1. Abbreviations used in this paper: CSA, cyclosporine; ET, endothelin; GFR, glomerular filtration rate; HVEC, human umbilical vein endothelial cells; RBF, renal blood flow; SMC, smooth muscle cells.

J. Clin. Invest.

(C) The American Society for Clinical Investigation, Inc. 0021-9738/91/07/0310/05 \$2.00

Volume 88, July 1991, 310-314 merular mesangial cells (GMC) which contain specific ET binding sites, resulting in cellular contraction and proliferation (413). Infusion of ET in animals results in vasoconstriction with a decrease in the glomerular filtration rate (GFR) and renal blood flow (RBF), as well as an increase in the mean arterial blood pressure (MAP) (14-16). Separate investigators have demonstrated inhibition of the vascular constrictive effects of ET by the administration of calcium channel blockers $(17,18)$, suggesting that the constrictive effects of ET are in part calcium channel dependent, the specificity of which is under investigation.

CSA, an immunosuppressive agent used widely in organ transplantation, has similar hemodynamic properties of ET (19). Upon infusion of CSA into animals, a decrease in the GFR and RBF occurs along with an increase in the MAP, contributing to diminished renal function (20). Calcium channel blockers have been used to decrease the degree of acute tubular necrosis and diminished renal function induced by CSA in transplanted allografts $(21,22)$.

Due to the parallel hemodynamic effects of CSA and ET upon SMC, we hypothesized that CSA may induce endothelin synthesis by endothelial cells which in turns acts upon vascular SMC. Also, knowing that the hemodynamic effects of both ET and CSA are somewhat blunted by the use of calcium channel blockers, we further hypothesized that if CSA stimulates the synthesis of ET, then the concomitant administration of calcium channel blockers may inhibit the SMC effects in the CSA recipient.

\section{Methods}

Tissue culture. Human umbilical vein endothelial cells (HVEC) were grown using standard techniques (23). The tissue culture media contained M199 (Sigma Chemical Co., St. Louis, MO), 0.015 M Hepes (Sigma Chemical Co.), Amphotericin $(0.025 \mathrm{mg} / \mathrm{ml}) /$ Penicillin $(100$ $\mathrm{U} / \mathrm{ml}) /$ Streptomycin $(100 \mathrm{mg} / \mathrm{ml}$ ) (Sigma Chemical Co.), and $10 \% \mathrm{Nu}-$ Serum (Collaborative Research, Bedford, MA) pH 7.3-7.4. HVECs were grown in $95 \%$ air and $5 \% \mathrm{CO}_{2}$ at $37^{\circ} \mathrm{C}$. Primary cultures were grown to confluency on $0.2 \%$ gelatin-coated (Sigma Chemical Co.) culture flasks and all experiments were carried out on first passage HVEC in 24- or 96-well plates (Fisher, St. Louis, MO). The HVECs were passaged using a $0.5 \mathrm{mg} / \mathrm{ml}$ trypsin and $0.25 \mathrm{mmol}$ EDTA solution (Sigma Chemical Co.). The endothelial cells were identified by their typical monolayer cobblestone appearance, positive immunofluorescence for anti-Factor VIII antibody (Bio Products for Science, Indianapolis, IN), and by their positive uptake of diacetytlated LDL (Biomedical Technologies, Stoughton, MA) $(23,23)$.

hSMC (CRL-1692) were obtained from the American Type Culture Collection (Rockville, MD). These cells were grown in media identical to that used with the HVEC in T-75 flasks (Fisher) until the proliferation experiments.

Pharmacologic agents used in these experiments included CSA in cremophor or cremophor alone (Sandoz Corp., Basel, Switzerland), Verapamil (Quad Pharmaceuticals, Inc., Indianapolis, IN), a sterile preparation of Nifedipine (Pfizer Laboratories, New York) cycloheximide (ICN Biomedical, Irving, CA), and PDGF (Sigma Chemical Co.). 
Both the RIA kit used to measure ET and the anti-ET antibody were purchased from Peninsula Laboratories, Belmont, CA. The crossreactivity of measured human ET using this kit is $100 \%$ of ET-1, and $7 \%$ with ET-2 and -3 each, while the anti-ET antibody preparation is $100 \%$ cross-reactive with human ET-1, -2 , and -3 .

First passage HVECs were plated in duplicate wells at a density of 25,000 cells per well in 24-well plates and allowed to grow to confluency (7-8 d) as determined by observation using a Nikon inverted microscope. At the time of confluency, the media was changed to 200 $\mu \mathrm{l}$ of media containing CSA in cremophor or equal concentrations of cremophor alone at concentrations of $0,50,100,200,300,400$, and $500 \mu \mathrm{g} /$ liter. These concentrations were chosen due to the range of therapeutic levels of CSA used clinically. After $24 \mathrm{~h}$ of incubation, the supernatants were removed and assayed for the presence of ET. This experiment was repeated on two separate occasions and the data is a summary of all three assays.

Next, we repeated the initial experiments incubating confluent HVECs with $200 \mu \mathrm{l}$ of media containing CSA at the previously described dosages, along with cycloheximide $(10 \mu \mathrm{g} / \mathrm{ml})$ for inhibition of protein synthesis. After $24 \mathrm{~h}$ of incubation, each supernatant was separately assayed for the presence of ET. As in the first set of experiments, these experiments were repeated on two separate occasions and the data is a summary of all three assays.

The initial experiment was again repeated and the media from CSA-treated HVEC (conditioned media) after $24 \mathrm{~h}$ of incubation was removed. $100 \mu$ l of conditioned media was combined with $100 \mu$ $(40,000)$ of $\mathrm{HSMC}$ and $50 \mu \mathrm{l}$ of $\left[{ }^{3} \mathrm{H}\right]$ thymidine $(20 \mu \mathrm{Ci} / \mathrm{ml})$ for proliferation studies as described by others (15). This experiment was then repeated in three separate experiments in the presence of $(a)$ anti-ET antibody $(1 \mu \mathrm{l} /$ well), $(b)$ Verapamil $(100 \mu \mathrm{g} / \mathrm{ml})$, or $(c)$ Nifedipine $(10$ $\mu \mathrm{M})$. Lastly, in order to exclude proliferative effects of CSA directly upon HSMC, CSA, in media at concentrations previously described, was incubated directly with HSMC and analyzed for proliferation. As in the first set of experiments, these experiments were repeated on two separate occasions and the data is a summary of all three assays.

We next evaluated calcium channel antagonists independent of CSA to insure that these agents did not have unto themselves direct effects upon hSMC. hSMC proliferation was evaluated as previously described in the presence of the following: (a) non-CSA (i.e., $0 \mu \mathrm{g} /$ liter CSA concentration) containing stock media not incubated with HVEC, $(b)$ non-CSA containing media incubated with HVEC for $24 \mathrm{~h}$, (c) non-CSA containing media incubated with HVEC for $24 \mathrm{~h}$ containing Verapamil, or $(d)$ Nifedipine. The concentration of calcium channel antagonists were as previously described. Each experiment was run on two separate occasions and the data is a summary of all three assays.

Finally, we looked at hSMC proliferation by an unrelated peptide to determine the specificity of the anti-ET antibody. In these experiments, parallel wells of $\left[{ }^{3} \mathrm{H}\right]$ thymidine-labeled hSMC were incubated in the presence and absence of $5 \mathrm{ng} / \mathrm{ml}$ of PDGF and analyzed for proliferation. These experiments were repeated in the presence of the anti-ET antibody at concentrations of $1 \mu \mathrm{l} /$ well. Each experiment was run on two separate occasions and the data is a summary of all three assays.

All incubations were carried out in duplicate and statistical significance was determined using the Student's $t$ test at $P<0.01$. Where applicable, the data is presented as the mean \pm SEM.

\section{Results}

Fig. 1 demonstrates a CSA dose-dependent increase of ET in the HVEC supernatants as compared with their basal synthesis $(P<0.01)$. The maximum synthesis of ET is $75 \%$ above basal levels resulting in a peak concentration of $75 \pm 3.2 \mathrm{mmol}$, which is in the range of ET synthesis reported by Chabrier et al. from unstimulated HVEC (17). Cremophor alone incubated with confluent HVEC failed to result in ET synthesis $(P<0.01)$.

Coincubation of CSA with cycloheximide resulted in di-

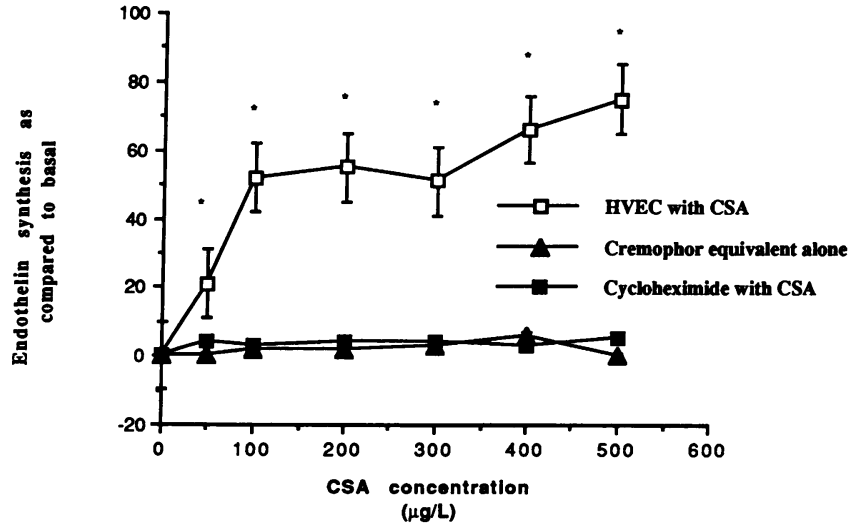

Figure 1. Measured ET in the supernatants of HVEC incubated with CSA (open boxes), cremophor equivalent alone (closed diamonds), or CSA and cycloheximide $(10 \mu \mathrm{g} / \mathrm{ml}$, closed boxes $)$, demonstrating ET synthesis by CSA-stimulated HVEC in a dose-dependent manner. Data is mean \pm SEM. ${ }^{*} P<0.01$.

minished amounts of ET within the supernatants with a peak concentration of ET of $5 \%$ above basal at $500 \mu \mathrm{g} /$ liter of CSA (Fig. 1). This is compared with the concentration of ET of $75 \%$ above basal at $500 \mu \mathrm{g} /$ liter of CSA alone $(P<0.01)$.

Conditioned media from the HVECs incubated with the CSA resulted in hSMC proliferation in a dose-dependent manner, whereas the direct incubation of CSA with hSMC resulted in no proliferation above basal levels $(P<0.01$, Fig. 2$)$. The conditioned media of the high dose CSA resulted in proliferation $114 \%$ above basal levels $(P<0.01)$. The degree of proliferation was diminished at all CSA concentrations of the conditioned media with the coincubation of a specific ET antibody $(P<0.01$, Fig. 2).

Separate coincubation of Verapamil and Nifedipine with hSMC and condition media resulted in inhibition of proliferation similar to that seen with the coadministration of the antiET antibody $(P<0.01$, Fig. 3$)$.

Comparison of hSMC proliferation by non-CSA containing media incubated with HVEC in the presence or absence of calcium channel antagonists failed to result in any statistical difference in hSMC proliferation (Fig. 4). Yet, comparison of HVEC-incubated media versus stock media did result in a significant increase in hSMC $(P<0.01$, Fig. 4).

Incubation of PDGF resulted in significant proliferation of hSMC as compared with baseline $(P<0.01)$, which was unaffected by the presence of anti-ET antibody (Table I).

\section{Discussion}

CSA-induced hemodynamic effects of diminished GFR and $\mathrm{RBF}$ as well as increased MAP have been shown to be due to progressive luminal narrowing of the afferent arteriole secondary to progressive SMC proliferation (25). Perico et al. recently have shown that the use of CSA results in the progressive increased peripheral vascular resistance leading to preglomerular vasoconstriction and eventual loss of glomerular blood flow (26). These studies provide a histologic basis of understanding of the changes in GFR with both the acute as well as the chronic administration of CSA. The use of CSA in recent renal allograft transplants results in a reversible form of renal insufficiency 


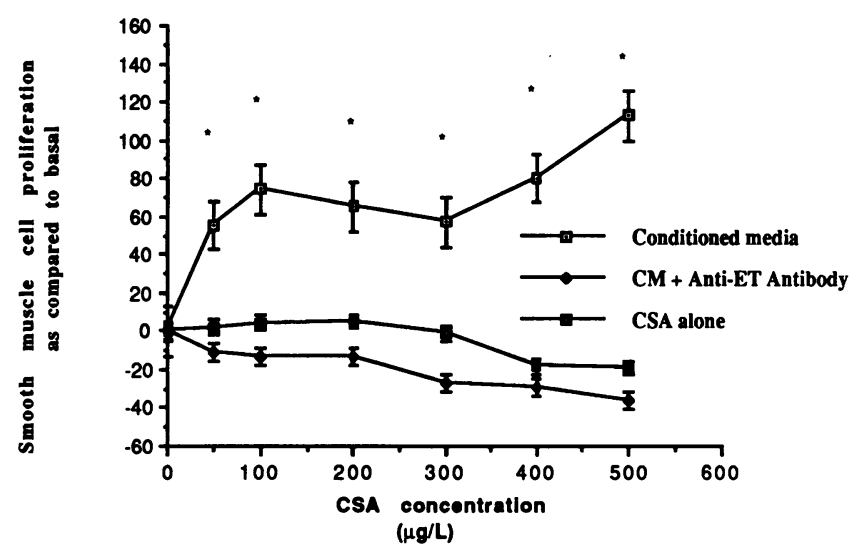

Figure 2. SMC proliferation of conditioned media (CM, open boxes), CM + anti-ET antibody (closed diamonds), or CSA with SMC alone (closed boxes), demonstration CM-induced SMC proliferation that appears ET specific. Data is mean \pm SEM. ${ }^{*} P<0.01$.

while the chronic use of CSA may lead to progressive and nonreversible renal failure $(27,28)$.

This vasoconstrictive effect of CSA does not totally explain the end result of irreversible loss of glomerular flow and localized thrombosis that may occur with chronic CSA administration $(29,30)$. The known effect of CSA upon endothelial cells as demonstrated in tissue culture experiments may contribute to the understanding of these irreversible changes. In vivo experiments have demonstrated that the direct incubation of CSA with vascular endothelial cells increased cell membrane disruption, as demonstrated by chromium 51 release, diminished $\mathrm{PgI}_{2}$ synthesis, diminished extracellular matrix production, and caused detachment of vascular endothelial cells (3136). Further, diminished Factor VIII, as demonstrated by in vivo techniques, occurs in the face of CSA exposure (36). This may be due to increased release of Factor VIII by endothelial cells, for Factor VIII levels have been shown to be increased in renal transplant patients receiving CSA (37).

Thus, this combination of vasoconstriction as well as direct effect of CSA upon vascular endothelial cells may additively result in the Shwartzman-like effect upon glomeruli $(29,30)$.

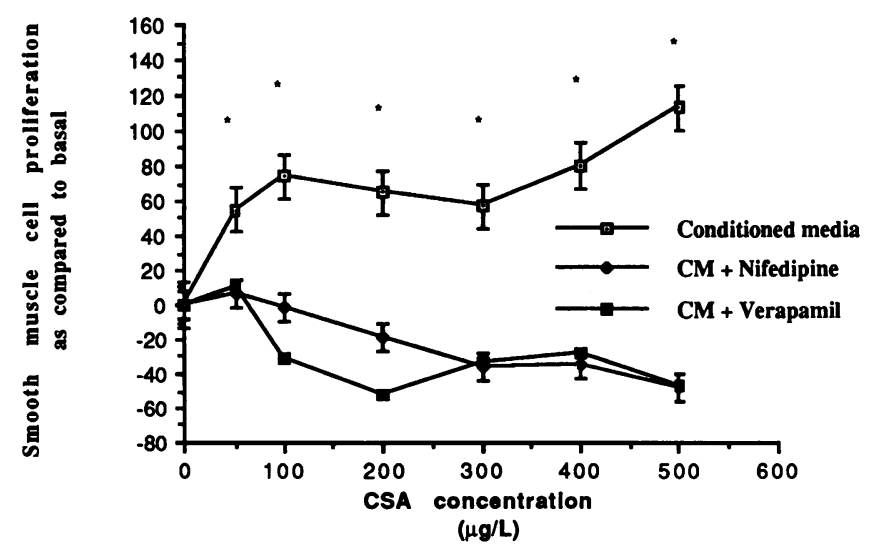

Figure 3. SMC proliferation of conditioned media (CM, open boxes), $\mathrm{CM}+$ Nifedipine $(10 \mu \mathrm{M}$, closed diamonds), or $\mathrm{CM}+$ Verapamil $(10 \mu \mathrm{g} / \mathrm{ml}$, closed boxes $)$, demonstrating inhibition of SMC proliferation by calcium channel antagonists. Data is mean \pm SEM. ${ }^{*} P<0.01$.

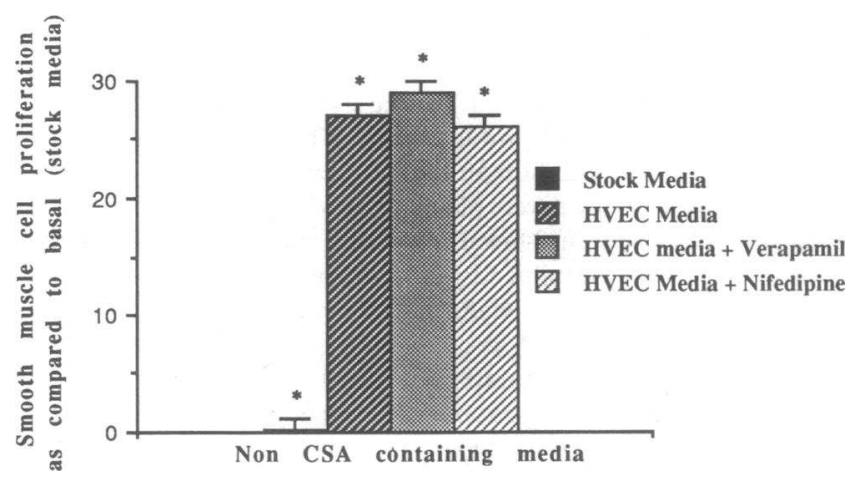

Figure 4. SMC proliferation by non-CSA ( $0 \mu \mathrm{g} /$ liter CSA) containing HVEC media occurring independently of the presence or absence of calcium channel antagonists (Not Significant). There is a significant increase in SMC proliferation from media incubated with HVEC as opposed to stock media not incubated with HVEC. Data is mean \pm SEM. ${ }^{*} P<0.01$.

The peptide endothelin has been found to be synthesized by endothelial cells derived from animals and humans (1-3). In tissue culture experiments, ET binds to specific binding sites on smooth muscle cells as well as glomerular mesangial cells resulting in proliferation and contraction $(4,11,12)$.

Due to its known vasoconstrictive effects, ET, as a causative agent in acute renal failure, has been suggested based on known hemodynamic animal data (38). Following this hypothesis in the area of transplantation, it has been speculated that ET is a contributor to the mechanism of CSA nephrotoxicity (39)

The etiology of the vasoconstrictive effects of CSA has been shown in animal experiments to be due to the presence of ET and its subsequent effect upon vascular $\operatorname{SMC}(26,40)$. In these studies, the vasoconstriction of CSA is reversed or prevented with either the coadministration or pretreatment with an antibody specific to ET. The applicability to human tissue is yet to be determined, for it is recognized that endothelial cells from animals and humans respond differently to identical stimuli $(41,42)$. Our findings of basal ET synthesis by HVEC that is increased with CSA provocation is supported by work of separate investigators. Clozel and Fischli have shown that ET is present in the supernatants of unstimulated HVEC (3), while Grieff et al. reported that plasma ET levels are increased in renal transplant recipients relative to the administration of CSA (43). Grieff et al. suggest that the mechanism of the vasoconstrictive effects of CSA is stimulation of vascular endothelial cells to synthesize ET, which in turn acts upon the perivas-

Table I. Smooth Muscle Cell Proliferation

\begin{tabular}{lccc}
\hline & $\begin{array}{c}- \text { Anti-ET } \\
\text { antibody }\end{array}$ & $\begin{array}{c}+ \text { Anti-ET } \\
\text { antibody }\end{array}$ & $P$ value \\
\hline \multicolumn{4}{c}{$c p m$} \\
-PDGF & $1655.75 \pm 144.46$ & $1760.5 \pm 276.88$ & NS \\
+ PDGF & $18,125.25 \pm 2403.28$ & $18,593.25 \pm 1764.99$ & NS \\
$P$ value & $<0.01$ & $<0.01$ & \\
& & &
\end{tabular}

PDGF-induced proliferation of smooth muscle cells which is not inhibited in the presence of anti-ET antibody. Data is presented as mean \pm SEM. 
cular smooth muscle cells, resulting in a diminished GFR and RBF. Finally, investigators have shown that CSA increases the ET binding sites in cardiac smooth muscle cells (44) and may possibly increase binding sites in other cells as well. Therefore, from these in vivo as well as in vitro studies, it is demonstrated that HVEC can synthesize ET, which is present in rodents as well as humans who receive CSA. Further, these animal studies reveal diminished RBF secondary to CSA, which is reversed with the coadministration of a specific antibody to ET $(26,40)$.

The use of CSA in recent renal allograft transplants results in a reversible form of renal insufficiency that is improved with the use of a calcium channel antagonist $(21,22)$. The prevention of posttransplantation ischemia by coadministration of a calcium channel antagonist may be partially explained by what is known of ET's effect upon vascular smooth muscle cells. The mechanism of action of ET to induce constriction of SMC involves influx of extracellular calcium (45). Conflicting studies indicate that the constrictive effects of ET upon SMC may be inhibited by calcium channel antagonists such as Verapamil or Nitrendipine, while other calcium channel antagonists such as Nifedipine or Diltiazem may have little effect $(7,17)$. This is further borne out in studies with Nicardipine. This dihydropyridine-sensitive calcium channel antagonist has been shown by some investigators to affect extracellular calcium influx into rodent SMC in response to ET stimulation, while other investigators are in disagreement $(4,18)$. This conflict may be due to methodologic or species variations.

Nitrendipine, used in clinical trials, as well as the other calcium channel antagonists available for clinical use (Verapamil, Nifedipine and Diltiazem) have each been shown to be effective for the use of hypertension as well as renal perfusion in the transplanted renal allograft $(46,47)$. Therefore, while calcium channel antagonists may have various responses to ET's effect upon SMC, clinically available calcium channel antagonists each appear to be useful for the treatment of hypertension and diminished RBF that is clinically evident in recipients of CSA $(21,22,47)$. This conflict between the clinical and in vivo effects of calcium channel antagonists may be due to hemodynamic effects of CSA other than that induced by ET. Other explanations include species as well as methodologic variations that require further investigation.

This study demonstrates that ET is present in the supernatants of CSA-stimulated HVEC in a CSA dose-dependent manner. The presence of ET appears to be an effect of synthesis as opposed to cytotoxicity, for ET is not found in the supernatants of CSA-stimulated HVEC in the presence of a protein synthesis inhibitor.

Knowing that ET stimulates SMC proliferation and contraction, we have demonstrated that ET present in the supernatants of CSA-stimulated HVEC induces hSMC proliferation. This effect is not a function of CSA upon hSMC, for these experiments show that no proliferation occurs when CSA is directly incubated with hSMC. Further, this study demonstrates that in the presence of a specific anti-ET antibody no proliferation occurs, supporting the hypothesis that the proliferative effect of the CSA-stimulated HVEC is from ET. To ensure that anti-ET antibody does not have specific proliferative inhibitory effects upon hSMC regardless of the cause of proliferation, platelet-derived growth factor (PDGF) was incubated with hSMC to induce proliferation. Comparing PDGF-induced proliferation in the presence or absence of anti-ET antibody, no significant difference in proliferation occurred. There- fore, the inhibition of conditioned media-induced $\mathrm{hSMC}$ proliferation by an anti-ET antibody appears to be specific to ET present in the conditioned media, thus supporting our hypothesis.

Calcium channel antagonists have been shown to inhibit ET-induced SMC proliferation and contraction (8). These studies support our interpretation that ET is present from CSAstimulated HVEC which subsequently induces hSMC proliferation. In the presence of calcium channel antagonists, hSMC proliferation from conditioned media is inhibited. We agree with Wallnofer et al. that this inhibition is not ET specific, yet more likely speaks to the mechanism of action of ET upon SMC (8). The suggestion that ET is an endogenous calcium channel agonist that can be specifically inhibited by calcium antagonists is tempting yet has been found not be valid. The calcium channel antagonist effect is parallel to that of other SMC mitogens (e.g., norepinephrine or $\mathrm{PGF}_{2}$ alpha) whose actions upon SMC also can be inhibited by calcium channel antagonists.

The findings presented here support the role of ET as a mediator of vasoconstriction with resulting hemodynamic effects due to CSA administration. The role of calcium antagonists as an approach to diminishing immediate posttransplantation renal allograft dysfunction is supported by our study, yet the mechanism of enhancing RBF by calcium channel antagonists may be due to a multitude of causes including ET-induced SMC constriction. Further studies are needed in order to identify other mediators of changes in renal hemodynamics. This study, in consort with others, may contribute to the further understanding of CSA-induced vasculopathy and hypertension, which may in turn result in specific ET as well as other antagonists for the prevention or reversibility of these problematic complications of CSA.

\section{Acknowledgments}

Funding for this project in part was from the Fleur-De-Lis/Cardinal Glennon Children's Hospital Grant program. The cyclosporine used in this project was a generous gift from Sandoz Corporation, Basel, Switzerland.

\section{References}

1. Yanagisawa, M., A. Inque, T. Ishikawa, Y. Kawuya, S. Kimura, S. Kumagaye, K. Najkajima, T. X. Watanabe, S. Sakakibara, K. Goto, and T. Masaki. 1988. Primary structure, synthesis, and biological activity of rat endothelin, an endothelium-derived vasoconstrictor peptide. J. Clin. Invest. 85:6964-6967.

2. Yanagisawa, M., H. Kurihara, S. Kimura, Y. Tomobe, M. Kobayshi, Y. Mitsui, Y. Yazaki, K. Goto, and T. Masaki. 1988. A novel potent vasoconstrictor peptide produced by vascular endothelial cells. Nature (Lond.). 332:411-415.

3. Clozel, M., and W. Fischli. 1989. Human cultured endothelial cells do secrete Endothelin-1. J. Cardiovasc. Pharmacol. 13(Suppl 5):S229-S231.

4. Hirata, Y, H. Yoshimi, S. Takata, T. X. Watanabe, S. Kumagai, K. Nakajima, and S. Sakaibara. 1988. Cellular mechanism of action by a novel vasoconstrictor endothelin in cultured rat vascular smooth muscle cells. Biochem. Biophys. Res. Commun. 154:868-875.

5. Komuro, I., H. Kurihara, T. Sugiyama, F. Takaku, and Y. Yoshio, 1988. Endothelin stimulates c-fos and c-myc expression and proliferation of vascular smooth muscle cells. FEBS (Fed. Eur. Biol. Soc.) Lett. 238:249-252.

6. Marsden, P. A., N. R. Danthuluri, B. M. Brenner, B. J. Ballermann, and T. A. Brock. 1989. Endothelin action on vascular smooth muscle involves inositor triphosphate and calcium mobilization. Biochem. Biophys. Res. Commun. 158:86-93.

7. Highsmith, R. F., D. C. Pang and R. M. Rapoport. 1989. Endothelial cell derived vasoconstrictors: mechanism of action in vascular smooth muscle. $J$. Cardiovasc. Pharmacol. 13(Suppl 5):S36-S44.

8. Wallnofer, A., S. Weir, U. Rueff, and C. Cauvin. 1989. The mechanism of 
action of endothelin as compared with other agonists in vascular smooth muscle. J. Cardiovasc. Pharmacol. 13(Suppl 5):S23-S31.

9. Badr, K. F., J. J. Murray, M. D. Breyer, K. Takahashi, T. Inagami, and R. C. Harris. 1989. Mesangial cell, glomerular and renal vascular responses to endothelin in the rat kidney. J. Clin. Invest. 83:336-342.

10. Simonson, M. S., S. Wann, P. Mene, G. R. Dubyak, M. Kester, and M. J.

Dunn. 1989. Endothelin-1 activates the phosphoinositide cascade in cultured glomerular mesangial cells. J. Cardiovasc. Pharmacol. 13(Suppl 5):S80-S83.

11. Simonson, M. S., and M. J. Dunn. 1990. Endothelin-1 stimulates contraction of rat glomerular mesangial cells and potentiates $\beta$-adrenergic-mediated cyclic adenosine monophosphate accumulation. J. Clin. Invest. 85:790-797.

12. Clozel, M., W. Fischli, and C. Guilly. 1989. Specific binding of endothelin on human vascular smooth muscle cells in culture. J. Clin. Invest. 83:1758-1761.

3. Orita, Y., Y. Fujiwara, S. Ochi, T. Takama, M. Fukunaga, and K. Yokoyama. 1989. Endothelin-1 receptors in rat renal glomeruli. J. Cardiovasc Pharmacol. 13(Suppl 5):S159-S161.

14. Goedtz, K. L., B. C. Wang, J. B. Madwed, J. L. Zhu, and R. J. Leadley, Jr. 1988. Cardiovascular, renal, and endocrine responses to intravenous endothelin in conscious dogs. Am. J. Physiol. 255:R 1064-1068.

15. Brenner, B. M., J. L. Troy, and B. J. Ballermann. 1989. Endothelium-dependent vascular responses. J. Clin. Invest. 84:1373-1378.

16. Kon, V., T. Yoshioka, A. Fogo, and I. Ichikawa. 1989. Glomerular actions of endothelin in vivo. J. Clin. Invest. 83:1762-1767.

17. Chabrier, P. E., M. Auguet, P. Roubert, M. O. Lonchrampt, V. Gillard, J. M. Guillon, S. Delaflotte, and P. Braquet. 1989. Vascular mechanism of action of endothelin-1: effect of $\mathrm{Ca}^{++}$antagonists. J. Cardiovasc. Pharmacol. 13(Suppl 5):S32-S35.

18. D'Orleans-Juste, P., M. Finet, G. de Nucci, and J. R. Vane. 1989. Pharmacology of endothelin-1 in isolated vessels: effect of nicardipine, methylene blue hemoglobin, and gossypol. J. Cardiovasc. Pharmacol. 13(Suppl 5):S19-S22.

19. Cohen, D. J., R. Loertscher, M. Rubin, N. L. Tilney, C. B. Carpenter, and T. B. Strom. 1984. Cyclosporine: a new immunosuppressive agent for organ transplantation. Ann. Int. Med. 101:667-682.

20. Murry, B. M., M. S. Paller, and T. F. Ferris. 1985. Effect of cyclosporine administration on renal hemodynamics in conscious rats. Kidney Int. 28:767 774.

21. Korb, S., G. Albornoz, A. A. Brems, and J. A. Light. 1989. Verapamil pretreatment of hemodynamically unstable donors prevents delayed graft function post-treatment. Transplant. Proc. 21:1236-1238.

22. Sobh, M. A., A. B. Shehab El-Din, F. E. Moustafa, M. A. El-Far, M. E. Hussein, H. M. Gad, and M. A. Ghoneim. 1989. A prospective randomized study of the protective effect of verapamil on ischemic renal injury in renal allotrans plants. Transplant. Proc. 21:1230-1232.

23. Jaffe, E. A., R. L. Nachman, C. G. Becker, and C. R. Minick. 1973 Culture of human endothelial cells derived from umbilical veins. Identification by morphologic and immunologic criteria. J. Clin. Invest. 52:2745-2756.

24. Voyta, J. C., D. P. Via, C. E. Butterfield, and B. R. Zetter. 1984. Identification and isolation of endothelial cells based on their increased uptake of acetylated-low density lipoprotein. J. Cell Biol. 99:2034-2040.

25. English, J., A. Evan, D. C. Haoughton, and W. B. Bennett. 1987. Cyclosporine-induced acute renal dysfunction in the rat. Transplantation (Baltimore) 44:135-141.

26. Perico, N., J. Dadan, and G. Remuzzi. 1990. Endothelin mediates the renal vasoconstriction induced by cyclosporine in the rat. J. Am. Soc. Nephol. 1:76-83.

27. Myers, B. D., J. Ross, L. Newton, J. Luetscher, and M. Perlroth. 1984 Cyclosporine-associated chronic nephropathy. N. Engl. J. Med. 311:699-705.
28. Renal histopathology in kidney transplant recipients immunosuppressed with cyclosporine A: results of an international workshop. 1985. Clin. Nephrol. 24:107-119.

29. Bunchman, T. E., S. M. Mauer, and Y. Kim. 1990. Effect of cyclosporin on generalized shwartzman reaction in diabetic rats. Diabetes. 39:83-86.

30. Vanrenterghem, Y., L. Roels, Y. Lerut, J. Gruwez, P. Michielsen, P. Gresele, H. Deckman, M. Coluci, J. Arnout, and J. Vermylen. 1985. Thromboembolic complications and haemostatic changes in cyclosporin-treated cadaveric kidney allograft recipients. Lancet. i:999-1002.

31. Zoja, C., L. Furci, F. Ghilardi, P. Zilio, A. Benigni, and G. Remuzzi. 1986. Cyclosporine-induced endothelial cell injury. Lab. Invest. 55:455-462.

32. Bunchman, T. E. Effect of cyclosporin-A on human vascular endothelium in tissue culture. 1989. Pediatr. Res. 24:336a. (Abstr.)

33. Brown, Z., and G. H. Neild. 1987. Cyclosporine inhibits prostacyclin production by cultured human endothelial cells. Transplant. Proc. 19:11781180.

34. Brown, Z., Neild, G. H., and G. P. Lewis. 1988. Mechanism of inhibition of prostacyclin synthesis by cyclosporine in cultured human umbilical vein endothelial cells. Transplant. Proc. 20(Suppl 3):654-657.

35. Neild, G. H., G. Rocchi, L. Imberti, F. Fumagalli, Z. Brown, G. Remuzzi, and D. G. Williams. 1983. Effect of cyclosporin A on prostacyclin synthesis by vascular tissue. Thromb. Res. 32:373-379.

36. Bunchman, T. E. and C. A. Brookshire. 1991. Cyclosporine inhibition of extracellular matrix by human vascular endothelium. Transplant. Proc. 23:332333.

37. Brown, Z., G. H. Neild, J. J. Willoughby, N. V. Somia, and J. S. Cameron. 1986. Increased factor VIII as an index of vascular injury in cyclosporin nephrotoxicity. Transplantation (Baltimore). 42:150-153.

38. Firth, J. D., A. E. G. Raine, P. J. Ratcliffe, and J. G. G. Ledingham. 1988. Endothelin: an important factor in acute renal failure? Lancet. ii:1179-1181.

39. Cairns, H. S., M. Rogerson, L. D. Fairbanks, J. Westwick, and G. H. Neild. 1988. Endothelin and cyclosporin nephrotoxicity. Lancet. ii:1496-1497.

40. Kon, V., M. Sugiura, T. Inagami, R. L. Hover, A. Fogo, B. R. Harvie, and I. Ichikawa. 1990. Cyclosporine (Cy) causes endothelin-dependent acute renal failure. Kidney Int. 37:486a. (Abstr.)

41. Harlan, J. M., L. A. Harker, M. A. Reidy, C. M. Gajdusek, S. M. Schwartz, and G. E. Striker. 1984. Lipopolysaccharide-mediated bovine endothelial cell injury in vitro. Lab. Invest. 48:269-274.

42. Harlan, J. M., L. A. Harker, G. E. Striker, and L. J. Weaver. 1983. Effects of lipopolysaccharide on human endothelial cells in culture. Thromb. Res. 29:1526.

43. Grieff, M., S. Al Shoheib, R. Loertscher, and D. J. Stewart. 1990. Cyclosporine A (CSA) induces elevation in circulating endothelin-1 (ET-1) following transplantation. J. Am. Soc. Neph. 1:758a. (Abstr.)

44. Nayler, W. G., X. H. Gu, D. J. Casley, S. Panagiotopoilos, J. Liu, and P. L. Mottram. 1989. Cyclosporine increases endothelin-1 binding site density in cardiac cell membranes. Biochem. Biophys. Res. Commun. 3:1270-1274.

45. Ishikawa, T., M. Yanagisawa, S. Kimura, K. Goto, and T. Masaki. 1988. Positive inotropic action of novel vasoconstrictor peptide endothelin on guinea pig atria. Am. J. Physiol. 255:H970-H973.

46. Wells, T. G., and A. R. Sinaiko. 1989. Antihypertensive efficacy and pharmacokinetics of nitrendipine in children. Pediatr. Nephrol. 3:C-191a. (Abstr.)

47. Dy, G., R. Raja, and M. Mendez. 1991. The clinical and biochemical effect of calcium channel blocker (CCB) in organ transplant recipients (TR) on cyclosporine (CsA). Transplant. Proc. 23:1258-1259. 